\section{Taking time out to get time back}

\section{Penny Barker}

With so many demands and everyone wanting a piece of you - both in your personal and professional life - it is important to be both effective and efficient with the time you have. Unfortunately, what often happens is that you get caught up on the hamster wheel, feeling out of control, not getting anything done or feeling that you are letting people down.

We often talk about 'time management' whilst what we really need to do is manage ourselves better and be purposeful and proactive with our time. In order to feel in control, we need to understand each of our roles and what are the priority tasks, both for us and for other people - what is important and what is urgent and how we differentiate between them. Once we have done this we can then determine which of the tasks we need to do, in what order, and which we can delegate or simply leave.

Procrastination leads to feelings of frustration and guilt. We often do it when we feel out of control which only reinforces the feeling of being overwhelmed. Taking active control of our tasks and our time and breaking things down into manageable, time-boxed chunks are just some of the strategies that can help us to make tangible progress.

Being aware of our own natural preferences is a key part of self-management. Some people are focused on results, which helps get things done but are they the right things? Others are more concerned with detail and accuracy, which creates high-quality work but can also lead to a lack of progress and decisionmaking. Some people love variety but this can lead to them volunteering for too many tasks with little sense of priority. Many people are great team players but find themselves putting the needs of other people ahead of their own and unable to say 'no'. Understanding how and why we trip ourselves up helps us to put strategies in place to overcome our natural tendencies, making us more effective and resilient.

Take time to think how you want to show up to the day and what you need to accomplish. Check in with yourself at regular intervals and assess whether you are on track or if things have changed; this helps to keep you in control and gives you time to think. It allows you to be flexible and responsive whilst still focusing on what's important to you.

\section{KEY LEARNING OBJECTIVES}

- Learn how to feel more in control by prioritizing your tasks effectively

- Understand what procrastination is and key strategies to overcome it

- Understand how being purposeful and proactive helps you to balance your roles in practice

\section{MULTIPLE CHOICE QUESTIONS}

1. Which book by Brian Tracy has great tips for beating procrastination?
(A) Eat that Frog!
(B) Eat that Camel!
(C) Eat that Horse!
(D) Eat that Giraffe!

2. Which is a useful way of prioritising tasks?
(A) Urgent, useful
(B) Urgent, important
(C) Important, useful
(D) Urgent, impactful

3. Which categories should all tasks go into?
(A) Do, dump, despair, decide
(B) Do, delegate, deliver, drop
(C) Deliver, dump, delegate, drop
(D) Do, ditch, defer, delegate

\section{The three Ps for having a good day: present, proactive and positive}

\section{Carolyne Crowe}

In order for us to be successful and happy in both our personal and professional lives, we need to know what's important to us and what outcomes we want to achieve. This allows us to be proactive in our approach to getting it, taking positive steps towards our goals and being present in the moment, aware of whether we are on track or if we need to take action to get back on course. This is the essence of personal leadership and helps us to get what we need and want from each day as well as fulfilling our roles and responsibilities.
What does a good day at work look and feel like for you? What's happening to make it a good day? Setting ourselves up for success requires a proactive and purposeful approach to our day. How can you start feeling refreshed and ready to go? What other preparations do you need to put in place to save you time and mental energy during the day?

Take time to consider your potential challenge points - what could stop you from having a good day? What outcomes do you need from these situations? Think about how you can approach these situations positively and with purpose.

During the day, try to be 'mindful' and keep yourself in the present - this stops your mind ruminating about the future and worrying about the past. Press pause periodically and check in with yourself. Think about what's going well and what needs to change to keep you on track. This allows you to keep a sense of control and to be aware of what's going on for you rather than being swept along by people and circumstance. 


\section{Congress}

Personal leadership is for everyone, whatever your position in practice. Actively working to be more present, proactive and positive will help you to have more good days and feel more fulfilled at work and at home.

\section{KEY LEARNING OBJECTIVES}

- Learning how to set yourself up for success on a daily basis, whatever the challenges

- Knowing the benefits of being present, proactive and positive through the day

- Defining what a 'good day at work' is for you and how to have more of them

\section{MULTIPLE CHOICE QUESTIONS}

1. Why is personal leadership is important?

(A) Everyone will follow you
(B) You are the boss

(C) It makes every day a good day

(D) It allows you to be in control of yourself and your time

2. What does being mindful require us to do?

(A) Be present and focus our attention on the moment

(B) Close our eyes and focus on breathing

(C) Meditate

(D) Be relaxed all the time

3. Why is having a good day important?

(A) The practice makes more money

(B) You get a lunch break every day

(C) You are happy, healthy and connected

(D) Everyone gets on all the time

\section{Leaning into colleagues, clients and cases}

\section{Carolyne Crowe}

Working with people is a key part of our profession; every day we are interacting with clients, colleagues and our bosses and this is often the part of the job that is most difficult and stressful. Do you find yourself frustrated by people not doing what you want or expect them to do, or in a conflict situation over something seemingly trivial? Do certain clients or colleagues make you feel anxious or irritated, or do you simply find some people hard to read or talk to?

We are taught to 'treat others like you would wish to be treated', but in reality, we need to treat others the way that they would wish to be treated. If we are able to do this, we are much more likely to get the best out of them and, in turn, to get the best out of any given situation. It means, however, that we need to know more about them. We also need to understand that people are not their behaviour; what we see and hear can give us useful information about how to interact with them, but we should refrain from judgement, as we know little about them at a deeper level.

People are different, but they are predictably different. Learning how to identify different behaviours and preferences gives you the opportunity to flex your own style; you cannot choose how another person will respond to you but you can maximize your chances of a positive response by communicating with them in the right way. Pay attention to how other people are interacting with you, both through their verbal and non-verbal communication. This helps you to develop your emotional intelligence (EI), being aware of yourself and of the impact that you are having on others. El is something that can be developed and is a key part of personal leadership.

Knowing more about the different behavioural styles allows you to recognize your own strengths and challenges.
It helps you to understand when you are tripping yourself up and when you are at your best. This allows you to communicate effectively and to influence positive behaviours. Through doing this you will improve your client interactions and get the best out of your colleagues, creating a happier and more productive working environment.

\section{KEY LEARNING OBJECTIVES}

- Understanding your own and others behaviours and preferences

- Knowing the key principles of emotional intelligence (EI) and why El is important

- Learning how to get the best out of every interaction

\section{MULTIPLE CHOICE QUESTIONS}

1. What are the the four different behavioural styles?

(A) Dominant, influencing, steady and compliant

(B) Direct, inspiring, slow and cautious

(C) Dominant, influencing, supportive and correct

(D) Determined, insightful, steady and critical

2. What does emotional intelligence require?

(A) Self-awareness and the ability to ability to manage ourselves

(B) A high $1 Q$

(C) To like everybody

(D) Everyone to have done behavioural profiling

3. What do you need to do to get the best out of others?
(A) Flex your style and pay attention to what happens
(B) Manipulate them
(C) Put people in boxes according to their style
(D) Not be yourself 